Conference Proceedings Paper

\title{
Longer-Lasting Episodes in the 2015 Ozone Season in Italy in Comparison with Recent Years
}

\author{
Serena Falasca 1,2,*, Annamaria Conte ${ }^{3}$, Carla Ippoliti ${ }^{3}$ and Gabriele Curci 1,2 \\ Published: 16 July 2016 \\ 1 Department pf Physical and Chemical Sciences, University of L'Aquila, L'Aquila post code, Italy; \\ serena.falasca1@univaq.it; gabriele.curci@aquila.infn.it \\ 2 Centre of Excellence CETEMPS, Department pf Physical and Chemical Sciences, University of L'Aquila, \\ L'Aquila post code, Italy \\ 3 Istituto Zooprfilattico dell'Abruzzo e del Molise 'G. Caporale', Teramo post code, Italy; \\ a.conte@izs.it (A.C.); c.ippoliti@izs.it (C.I.) \\ * Correspondence: serena.falasca1@univaq.it; Tel.: +39-0862-433087
}

\begin{abstract}
The year 2015 is considered the hottest on records at the global scale, since reliable temperature measurements are available. Ambient air quality is strongly influenced by meteorological conditions, and daytime surface ozone concentrations are generally positively correlated with temperatures. We thus analysed 2015 ozone data over Italy to check if exceptional ozone values reflected the exceptional temperatures. To this end, we evaluated the ozone season in 2015 compared to the 2002-2015 trend, using data from 24 selected monitoring stations and analyzing the exceedances of limit values imposed by the European directive. We found that 2015 was one of the hottest years over Italy, and the ozone season was one of the most severe in the last ten years. In 2015, the average duration of ozone episodes (the number of consecutive days with daily maximum 8-hour-average values higher than the threshold of $120 \mu \mathrm{g} \cdot \mathrm{m}^{-3}$ ) was about 4 days, similar to that of 2006 and less than that of 2003 which was about 5 days. This duration is longer than the average observed in recent years, which is less than 3 days. Furthermore, the mean maximum concentration of ozone events was the second on record together with 2006, after the notable heatwave of 2003.
\end{abstract}

Keywords: ozone; air quality; temperature; heat wave; Italy; ozone trend

\section{Introduction}

According to a new WHO report [1], ozone and other short-lived climate pollutants are responsible for diseases that kill 7 million people per year. Ozone $\left(\mathrm{O}_{3}\right)$ is a secondary pollutant produced in the troposphere when carbon monoxide, methane, or other volatile organic compounds VOCs are oxidized by the hydroxyl radical $(\mathrm{OH})$ in presence of reactive nitrogen oxides $(\mathrm{NO})$ and sunlight $[2,3]$. These species $\left(\mathrm{CO}, \mathrm{CH}_{4}\right.$, non-methane VOCs and $\mathrm{NO}_{\mathbf{x}}$ ) are called "ozone precursors" and the period from May through September is considered the "O $\mathrm{O}_{3}$ season" due to the high ozone concentrations characterizing these months and the photochemical nature of the process.

Ambient air quality in Europe is regulated by directives that establish limit values (with possible permitted excesses each year) and exposure related objectives. The observance of these directives includes actions aimed at the control of relevant emissions sectors such as transportation, energy production and building heating.

Air quality is also heavily influenced by meteorological conditions. [3] made a list of the meteorogical variables to which air quality is sensible and outlined the entity of the dependence; 
The 1st International Electronic Conference on Atmospheric Sciences (ECAS 2016), 16-31 July 2016; Sciforum Electronic Conference Series, Vol. 1, 2016

their list included temperature, regional stagnation, wind speed, mixing depth, humidity, cloud cover, precipitation. The linkage between air quality and meteorological variables (temperature, humidity, stability, wind speed, mixing depth, cloud cover, precipitation, radiation flux, ozone precursors concentration) was explored though a variety of statistical methods: [4] used multiple linear regression analysis, while [5] examined and compared three regression-based approaches including also a circulation type classification. [6] used quantile regression analysis.

Air quality is also heavily influenced by meteorological conditions. [3] made a list of the meteorogical variables to which air quality is sensible and outlined the entity of the dependence; their list included temperature, regional stagnation, wind speed, mixing depth, humidity, cloud cover, precipitation. The linkage between air quality and meteorological variables (temperature, humidity, stability, wind speed, mixing depth, cloud cover, precipitation, radiation flux, ozone precursors concentration) was explored though a variety of statistical methods: [4] used multiple linear regression analysis, while [5] examined and compared three regression-based approaches including also a circulation type classification. [6] used quantile regression analysis.

[7] examined observational data in the eastern US over 21 years, since 1997: the geographical area was divided into four chemically coherent receptor regions and the target time period into two "emissions regimes", including years till 2002 and after 2002 when a power plant NOx emissions control program took place in US. The relationship showed a decreasing slope after 2002, consistently with the reduction on power plant emission of NOx. [11] investigated mechanisms and parameters that control ozone variability, in particular radon concentration and meteorological parameters. They found a dominant influence of of horizontal advection and vertical mixing in the planetary boundary layer in the control of ozone variability at their site.

Since the effect of the temperature on the ozone production is well-established and recognized, this work stems from the question on how the heat wave occurred in the summer of 2015 affected the ozone season in the same year. Such investigation is the aim of this work and requires a quantitative examination of the 2015 ozone season, also in comparison to recent years. Therefore a dataset of ozone concentrations from 24 stations across Italy is assembled and analyzed for the 2002-2015 period. A comparison of ozone seasons occurring during these years has been performed in terms of the number of exceedences of limit values set by the European directive. A cluster analysis technique of high-ozone concentrations is also applied in order to identify and characterize ozone events during the target period. Moreover, temperature observations temperature observations are collected for the same period and the relationship between ozone and temperature is explored. The cluster analysis technique is applied also to the temperature so as to indentify high-temperature events, or heat waves, and to study the link with ozone events.

\section{Material and Methodology}

\subsection{Ozone and Meteorological Data}

Ozone concentrations for the period 2013-2015 from 259 stations air quality monitoring stations of the Regional Environmental Protection Agencies (ARPAs) across the Italian Peninsula were acquired through the AirBase portal (http://acm.eionet.europa.eu/databases/airbase/), available Agencies' web services (e.g., http://www2.arpalombardia.it), and through direct contact of Agencies for the period. For the years 2002-2012 data from the AirBase portal was retrieved.

According to the Decision 2001/752/CE and to the document "Criteria for EUROAIRNET", air quality monitoring stations are classified through two criteria: the area type where they are localized (i.e., the "zone") and the type of station in relation to dominant emission sources (i.e., the "type"). Three zones and three types of types of stations are defined: rural (R), suburban (S) and urban (U) zones, and traffic (T), industrial (I) and background (B) stations (2001/752/CE). 
The 1st International Electronic Conference on Atmospheric Sciences (ECAS 2016), 16-31 July 2016; Sciforum Electronic Conference Series, Vol. 1, 2016

\subsection{Selection of Air Quality Monitoring Stations}

Among the 259 ARPA stations, 24 stations were selected following three criteria: availability of ozone data for 2015, availabiliry of at least 75\% of ozone data for 2002-2014 years, and availability of a nearby weather station. The 24 selected stations were grouped according to the zone (rural, suburban, urban) and based on the geographical area, namely outside or inside the Po Valley. Po Valley is a flat area in Northern Italy surrounded by the Alps and the Appennines mountains and the Adriatic Sea. This geographical classification is motivated by the outstanding levels of pollution that characterize this region, compared to most of European areas [12,13]. Therefore, six classes of stations were identified, populated as follows: 1 rural, 8 suburban and 4 urban outside the Po Valley (Non Po Valley group); 3 rural, 1 suburban and 7 urban inside the Po Valley (Po Valley group). The location of the ozone stations is showed in Figure 1, with different markers denoting the zone and different colors denoting the geographical location (inside/outside Po Valley). The list of the selected stations is reported in Table 1, together with their international identification codes, names, types, zones, geographical coordinates and location with respect to the Po Valley. The analysis is limited to the ozone season of each year, that is the period from May to September.

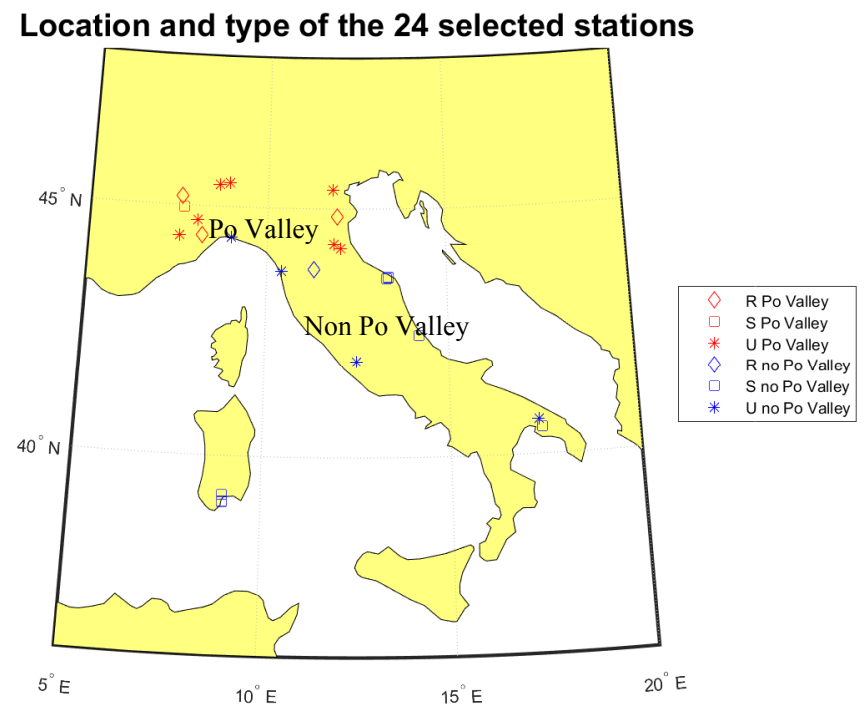

Figure 1. Location of the selected ozone monitoring stations across the Italian Peninsula, classified according to their zone and geographical location. The red color denotes "Po Valley" stations, while blue color denotes “Non Po Valley" stations. Markers denote rural (diamond), suburban (square), and urban (asterisk) zone.

\subsection{Data Analysis}

The air quality European Directive 2008/50/EC [14] has been implemented in Italy with the D.Lgs. 155/2010 that defines limit values of ozone concentration for the protection of human health and vegetation. The following thresholds are specified: a long-term objective (hereinafter LTO), an information threshold (hereinafter IT) and an alert threshold (AT); LTO is expressed in terms of daily maximum eight-hour running mean and is equal to $120 \mu \mathrm{g} \cdot \mathrm{m}^{-3}$; IT and AT are expressed in terms of hourly averaged value and are equal to $180 \mu \mathrm{g} \cdot \mathrm{m}^{-3}$ and $240 \mu \mathrm{g} \cdot \mathrm{m}^{-3}$, respectively. The number of exceedences of LTO and IT thresholds are computed for each year and analyzed in section 3. AT values are not analyzed since their numbers are relatively small (not shown).

A cluster analysis of the data is also performed. We define as "cluster" a subset of consecutive days for which the LTO threshold is exceeded. We also define another set of clusters based on temperature, setting a threshold of $28^{\circ} \mathrm{C}$. 
The 1st International Electronic Conference on Atmospheric Sciences (ECAS 2016), 16-31 July 2016;

Sciforum Electronic Conference Series, Vol. 1, 2016

Table 1. List of ozone monitoring stations selected for analysis: Exchange of Information (EoI) code, name, type, zone, geographical coordinates and location with respect to the Po Valley. Station type: B-Background, I-Industrial, T-Traffic, Un-Unknown; Station zone: R-Rural, S-Suburban, U-Urban.

\begin{tabular}{|c|c|c|c|c|c|c|}
\hline EoI Code & Name & Type & Zone & Latitude & Longitude & Location \\
\hline IT1397A & CENAS8 & I & $S$ & 39.222999 & 8.998000 & Non Po Valley \\
\hline IT1270A & CENSA1 & I & S & 39.082001 & 9.0120001 & Non Po Valley \\
\hline IT1269A & CENSA2 & I & S & 39.069999 & 9.0170002 & Non Po Valley \\
\hline IT0459A & CHIARAVALLE2 & Un & $S$ & 43.598999 & 13.342000 & Non Po Valley \\
\hline IT1524A & CN_4003_ALBA & Un & $\mathrm{U}$ & 44.703998 & 8.0329999 & Po Valley \\
\hline IT1529A & CN_4078_CUNEO & Un & $\mathrm{U}$ & 44.381999 & 7.538000 & Po Valley \\
\hline IT1519A & CN_4201_SALICETO & $\mathrm{B}$ & $\mathrm{R}$ & 44.414001 & 8.1680002 & Po Valley \\
\hline IT0463A & FALCONARA ALTA & Un & S & 43.620998 & 13.390000 & Non Po Valley \\
\hline IT0461A & FALCONARA SCUOLA & Un & $S$ & 43.632999 & 13.387999 & Non Po Valley \\
\hline IT0883A & FI-SETTIGNANO & $\mathrm{B}$ & $\mathrm{R}$ & 43.789001 & 11.324000 & Non Po Valley \\
\hline IT1179A & Gherardi & B & $\mathrm{R}$ & 44.8 & 11.9 & Po Valley \\
\hline IT1679A & Grottaglie & B & $S$ & 40.537998 & 17.423999 & Non Po Valley \\
\hline IT1010A & MAGENTA VF & B & $\mathrm{U}$ & 45.466999 & 8.8929996 & Po Valley \\
\hline IT1680A & Martina Franca & $\mathrm{T}$ & $\mathrm{U}$ & 40.701000 & 17.332001 & Non Po Valley \\
\hline IT1518A & NO_3106_VERDI & Un & $\mathrm{U}$ & 45.437999 & 8.6210003 & Po Valley \\
\hline IT1030A & PARCO BUCCI & Un & $\mathrm{U}$ & 44.283000 & 11.871000 & Po Valley \\
\hline IT1048A & PARCO RESISTENZA & Un & $\mathrm{U}$ & 44.215000 & 12.048000 & Po Valley \\
\hline IT1453A & PD-Mandria & $\mathrm{B}$ & $\mathrm{U}$ & 45.372001 & 11.842000 & Non Po Valley \\
\hline IT1110A & PI-PASSI & B & $\mathrm{U}$ & 43.738998 & 10.402000 & Non Po Valley \\
\hline IT0858A & QUARTO & B & $\mathrm{U}$ & 44.395999 & 8.9919996 & Non Po Valley \\
\hline IT1423A & TEATRO D'ANNUNZIO & B & $S$ & 42.456001 & 14.211000 & Non Po Valley \\
\hline IT1121A & TO_1099_MANDRIA & B & $\mathrm{R}$ & 45.175999 & 7.5599999 & Po Valley \\
\hline IT1125A & TO_1309_VINOVO & B & S & 44.960998 & 7.6360001 & Po Valley \\
\hline IT0953A & VILLA ADA & B & U & 41.936001 & 12.501000 & Non Po Valley \\
\hline
\end{tabular}

\section{Results and Discussion}

\subsection{Ozone Exceedences of Directive Limit Values and Temperature}

The temporal trend of the number of exceedences of the ozone limit values set by the European directives was computed and analysed for ozone seasons from year 2002 to 2015. Moreover, the link between ozone and temperature is examined, also through the slopes of the ozone-temperature relationship for the six classes of stations.

Figure 2 and 3 show the number of exceedences of LTO (daily maximum 8-hour average of $120 \mu \mathrm{g} \cdot \mathrm{m}^{-3}$ ) and IT (1-hour average of $180 \mu \mathrm{g} \cdot \mathrm{m}^{-3}$ ) for each year, for all 24 selected stations and for the six classes of stations, respectively. Because of the well-known crucial role of the temperature in the ozone production, the average daily maximum temperature is also reported. 
The 1st International Electronic Conference on Atmospheric Sciences (ECAS 2016), 16-31 July 2016; Sciforum Electronic Conference Series, Vol. 1, 2016

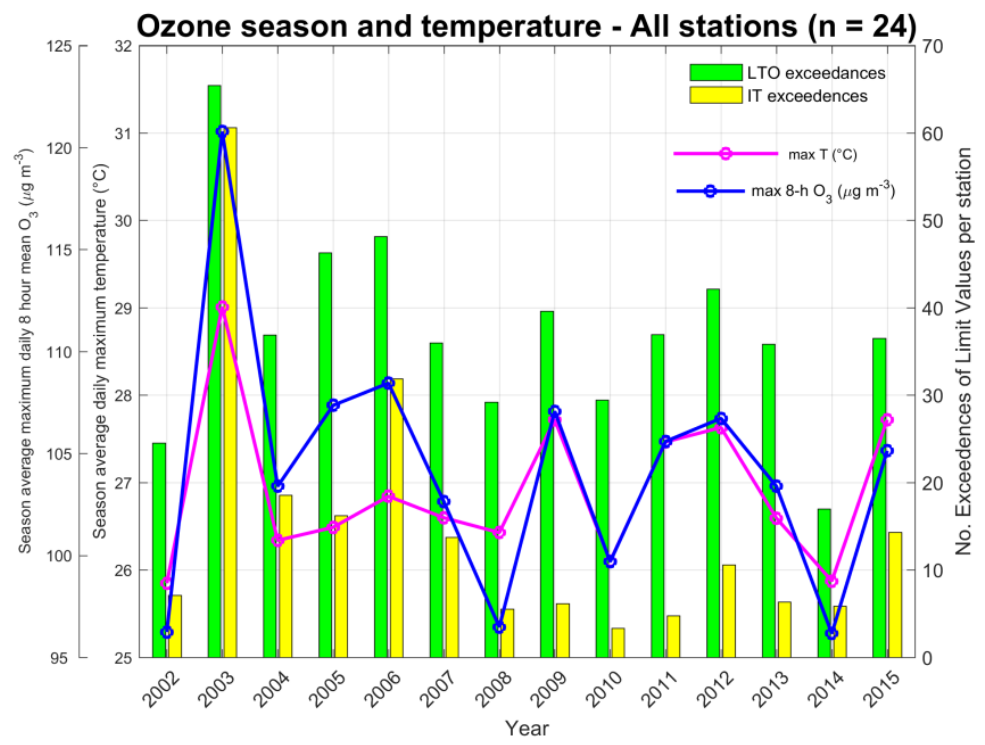

Figure 2. Number of ozone exceedances, maximum ozone averages and maximum temperatures for all stations. Number of exceedences of ozone limit values per station for the years 2002-2015 during the ozone season (May to September); green bars denote the exceedences of the daily maximum 8-hour-average of the $120 \mu \mathrm{g} \cdot \mathrm{m}^{-3}$ threshold (long-term objective, LTO), yellow bars denote those of the hourly ozone of the $180 \mu \mathrm{g} \cdot \mathrm{m}^{-3}$ threshold (information threshold, IT). Lines denote the season average daily maximum 8-hour ozone (blue), and the season average daily maximum temperature (magenta).

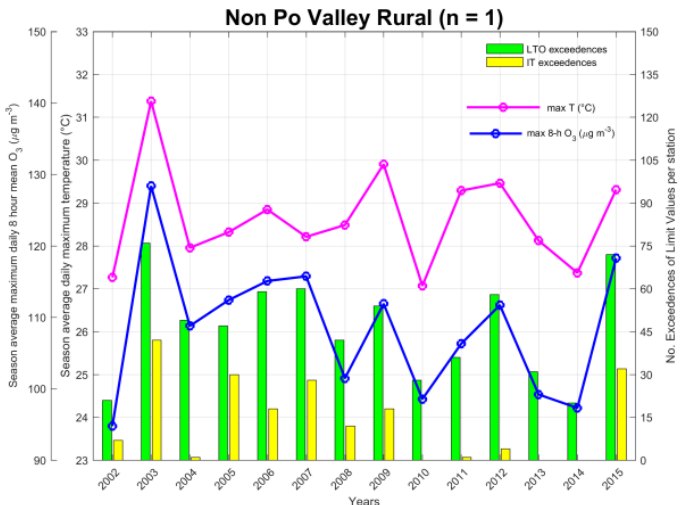

(a)

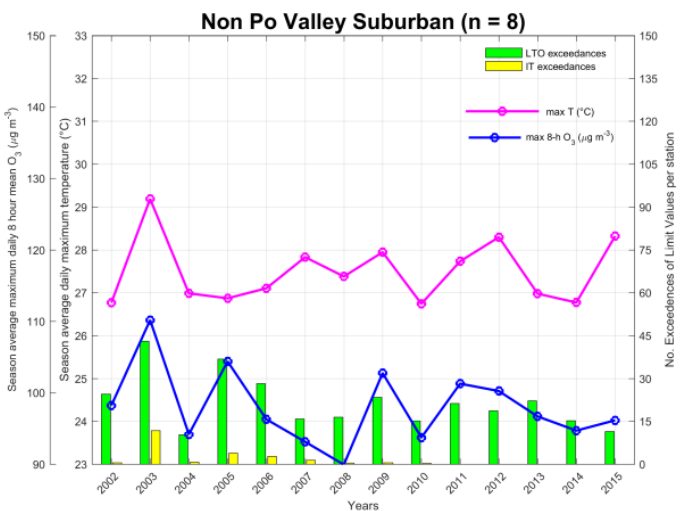

(c)

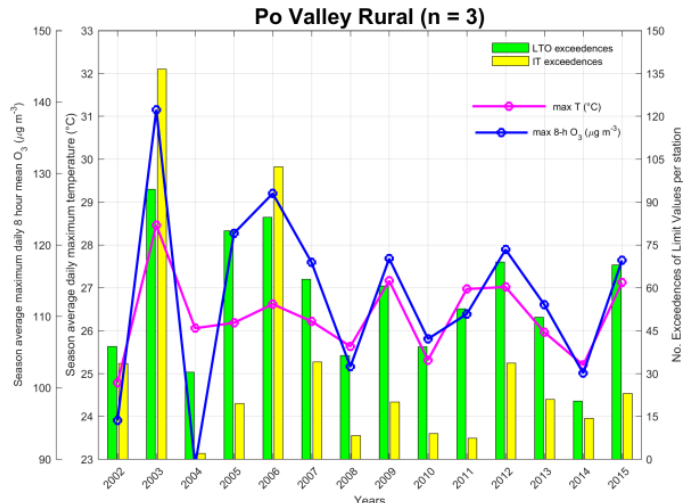

(b)

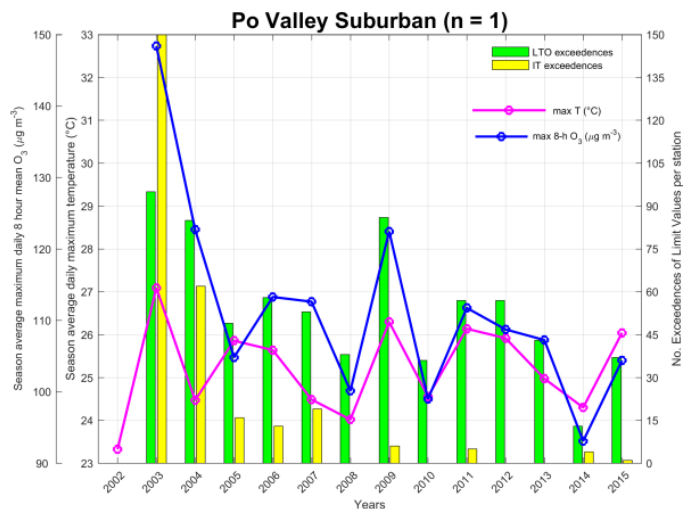

(d)

Figure 3. Cont. 
The 1st International Electronic Conference on Atmospheric Sciences (ECAS 2016), 16-31 July 2016; Sciforum Electronic Conference Series, Vol. 1, 2016

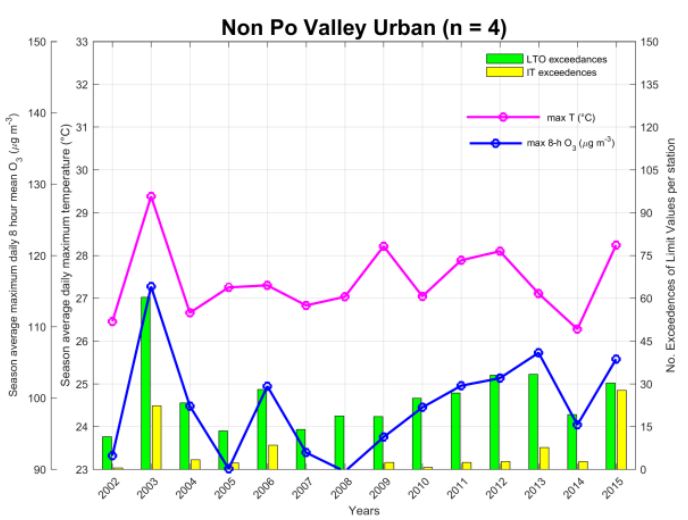

(e)

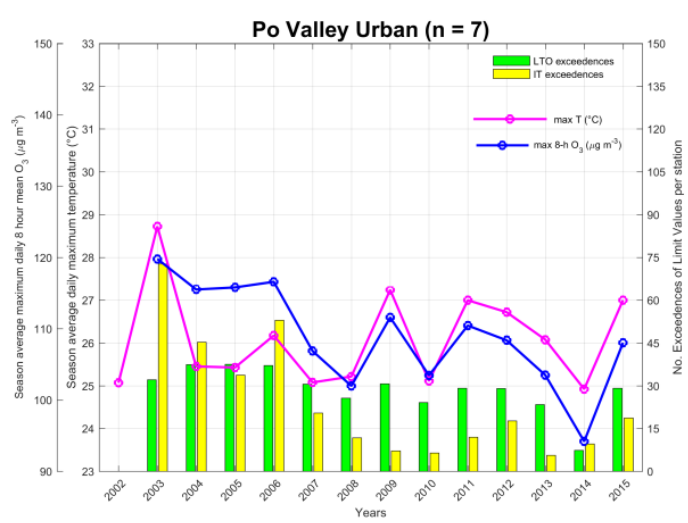

(f)

Figure 3. Number of ozone exceedances, maximum ozone averages and maximum temperatures (as in Figure 2) for stations grouped as follows: Rural stations (a) outside the Po Valley and (b) inside the Po Valley; Suburban stations (c) outside the Po Valley and (d) inside the Po Valley; Urban stations (e) outside the Po Valley and (f) inside the Po Valley.

Considering all stations (Figure 2), the year 2003 shows the maximum number of LTO exceedences (about 65 per station); that year is also characterized by an important heat wave, as proved by the highest value of the average maximum temperature $\left(29^{\circ} \mathrm{C}\right)$. Years 2006 and 2005 have respectively the second and the third higher number of LTO exceedences (almost 50), while the temperature is about $26.5-27^{\circ} \mathrm{C}$, similar values of some years with a lower number of exceedences (2009, 2011, 2012, 2015). Probably during the 2005 and 2006 ozone seasons, other factors than temperature strongly influenced the ozone production. This phenomenon requires an in-depth analysis that is beyond the aim of this work. Years 2012 and 2009 also have high numbers of exceedences ( 40 and 42) and are characterized by high values of mean temperature (about $28{ }^{\circ} \mathrm{C}$ ). The number of LTO exceedences in 2015 was 38 per station, and it is about the same as in 2004, 2007, 2011 and 2013, and also temperature is similar to those years with the exception of 2004, which has a lower temperature. It is possible to identify two groups of three consecutive years (2004-2006 and 2010-2012) with increasing number of exccedences, mean temperature and ozone values. Figure 2 reveals that generally the temporal trend of mean ozone concentration and number of exceedences for LTO reflects the temporal trend of temperature.

The number of IT excedences is always lower than the number of LTO excedences, and there is a general decrease in their number in recent years (after 2007). The LTO appears to be the critical parameter to be looked at with special attention when assessing the contribution of ozone to air quality levels in Italy. The latter point is reinforced by noting that, according to the European directive, LTO must not be exceeded more than 25 times per calendar years, averaged over three years: Figure 2 shows that the number of LTO exceedences was often higher than 25 on average in recent years, and it may thus represent an issue for air quality compliance in Italy.

Figure 3 shows the number of exceedences of LTO and IT for the six classes of stations. Stations in the Po Valley (Figure 3b,d,f) have generally higher ozone concentrations and an higher number of exceedences compared to stations outside the Po Valley (Figure 3a,c,e). However, the temperatures are generally higher outside the Po Valley, indicating it is not the only driver of high ozone episodes. The 2003 was the year with he most severe ozone season, having 135 and 150 IT exceedences in the Po Valley, at rural and suburban stations, respectively. The 2015 ozone season was one of the most severe over Italy in recent years, especially in terms of LTO exceedences at rural stations (about 70). The least number of exceedences is observed at urban stations inside Po Valley and at suburban stations outside Po Valley. 
Figure 4 displays the monthly distribution of LTO exceedences at all stations. The distribution generally peaks in July, with the exception of 2011, 2012 and 2014. In 2011, the number of LTO exceedences in May were the same as in August.
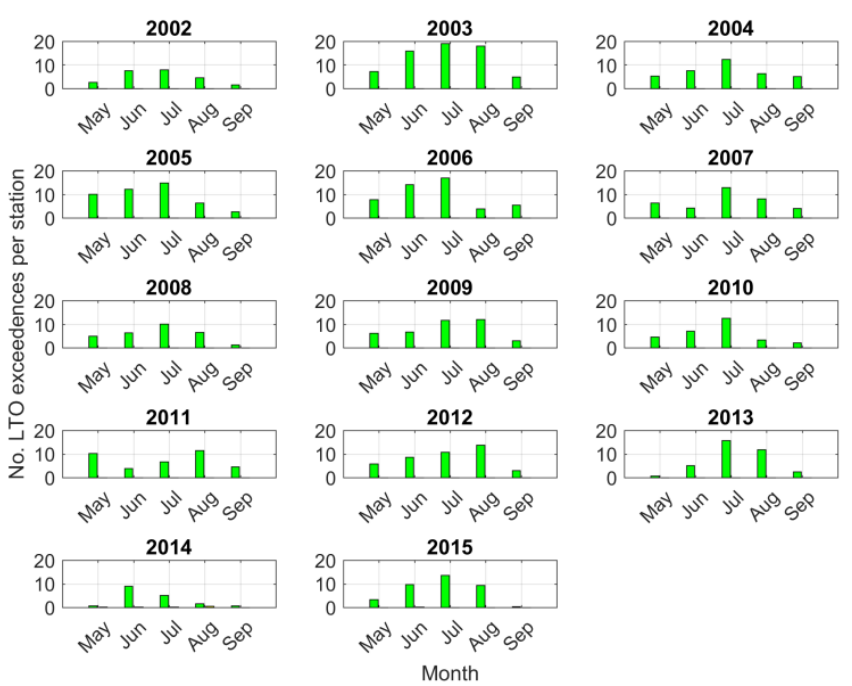

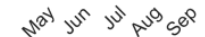

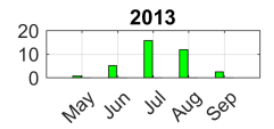

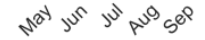

(May-September). All selected stations are included.

Figure 5 shows the mean slope of the linear regression between the maximum temperature and maximum 8-hour average ozone for the six classes of stations. In general, we found more sensitivity to the temperature (higher slope) in Po Valley, where the slopes are generally higher at urban stations. Outside Po Valley, the slopes are generally higher at rural stations and lower at urban stations. A decreasing tendency is observed for slopes from 2003 to 2011, afterwards there is an inversion of tendency. [7] reported a decrease of slopes after 2002 over the US, and attributed it to the programmed reduction of $\mathrm{NO}_{x}$ emissions.

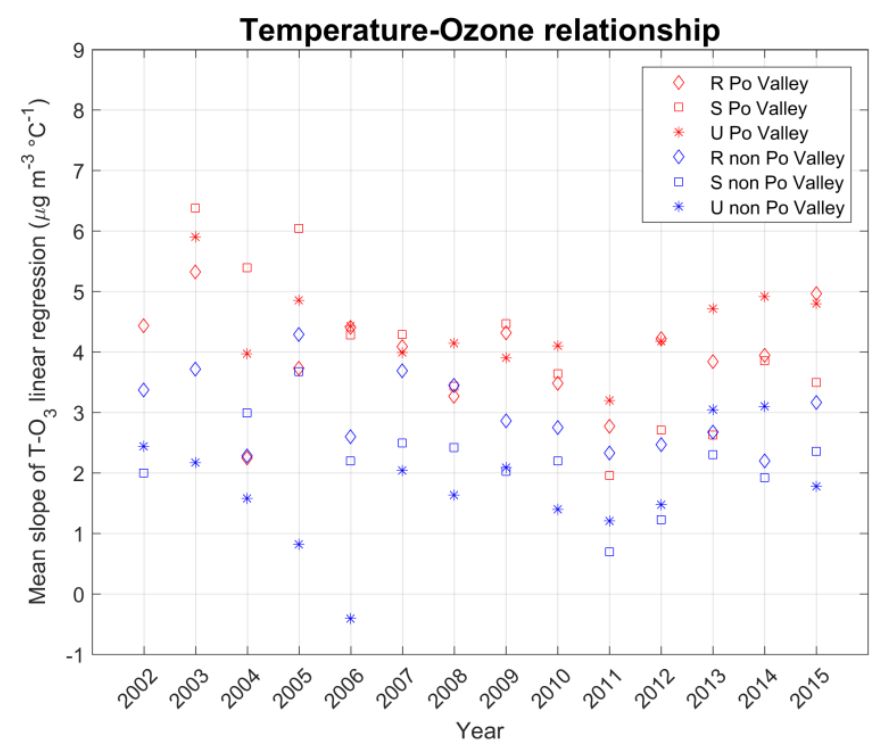

Figure 5. Slope of the linear regression beetwen the daily maximum temperature and the maximum 8-hour mean ozone, for the six classes of stations shown in Figure 1. 
The 1st International Electronic Conference on Atmospheric Sciences (ECAS 2016), 16-31 July 2016; Sciforum Electronic Conference Series, Vol. 1, 2016

\subsection{Cluster Analysis}

The same dataset was analysed grouping the enhanced ozone and temperature episodes in multi-day clusters: an "ozone cluster" is a subset of consecutive days in which the LTO threshold is exceeded. Based on temperature, a cluster is a subset of consecutive days registering maximum temperature beyond $28{ }^{\circ} \mathrm{C}$. Figure 6 displays, for each year, the number of clusters per station, average cluster duration (days), maximum cluster concentration, and mean cluster concentration. Boxplots show the distribution of data calculated at each of the 24 stations. The red line in the box denotes the median, the edges of the box denote the 25th and 75th percentile, the wiskers have length of 1.5 times the interquartile ranges, the markers denote the outliers. The number of ozone episodes is between 10 and 15 per year, with no particular trend. The year 2015 had 10 ozone events, like 2010, one of the lowest values (Figure 6a). The average duration of these events is about 2.5-3 days, with notable exception in 2003 (5 days), and 2006 and 2015 (4 days) (Figure 6b). Interestingly, 2015 has also the median value of 4 days, while all other years, including 2003, have medians around 3 days. The year 2003 had also the highest maximum and mean ozone concentration during the episodes (about 145 and $135 \mu \mathrm{g} \cdot \mathrm{m}^{-3}$, respectively) (Figure 6c,d). Maximum concentrations were high also in 2006, 2007 and 2015 (about $140 \mu \mathrm{g} \cdot \mathrm{m}^{-3}$ ), while the mean concentration display a relatively flat trend (with the exception of year 2003).

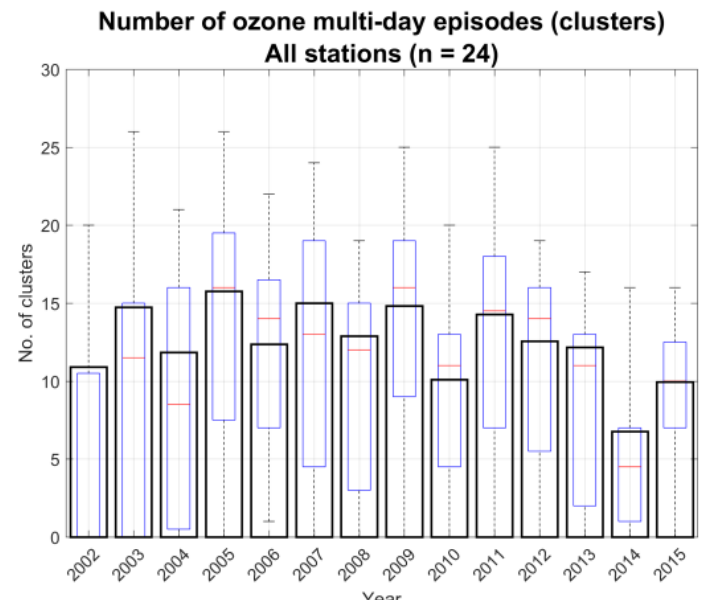

(a)

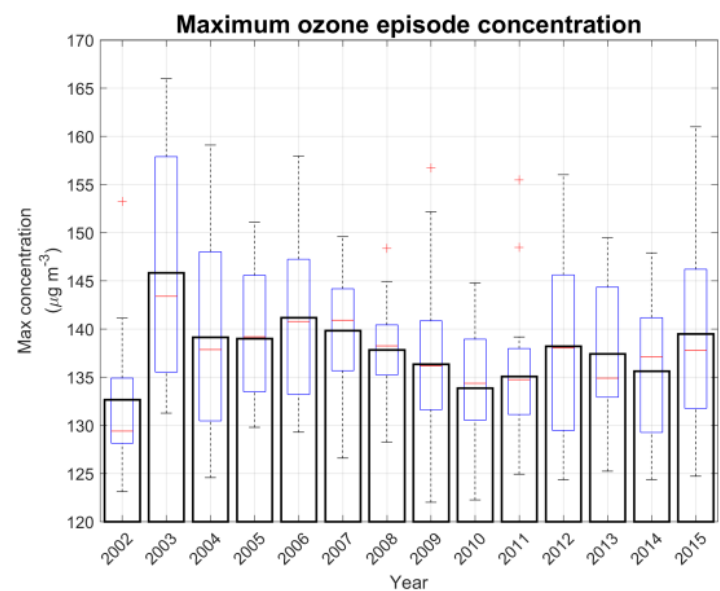

(c)

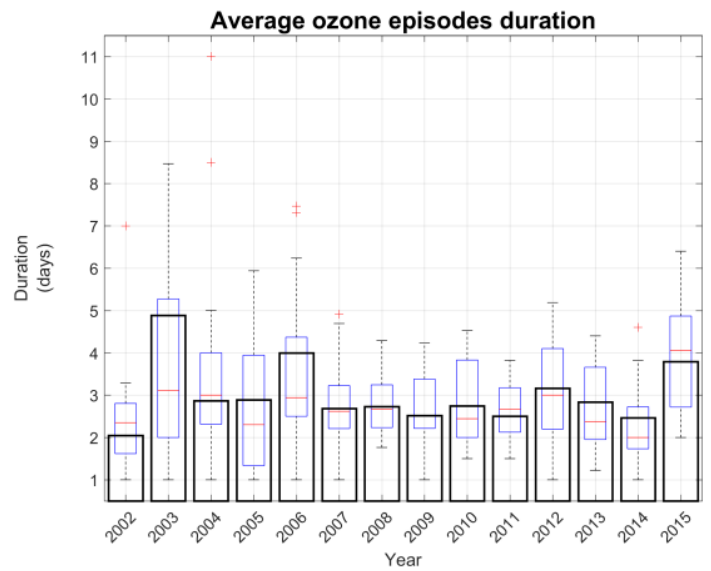

(b)

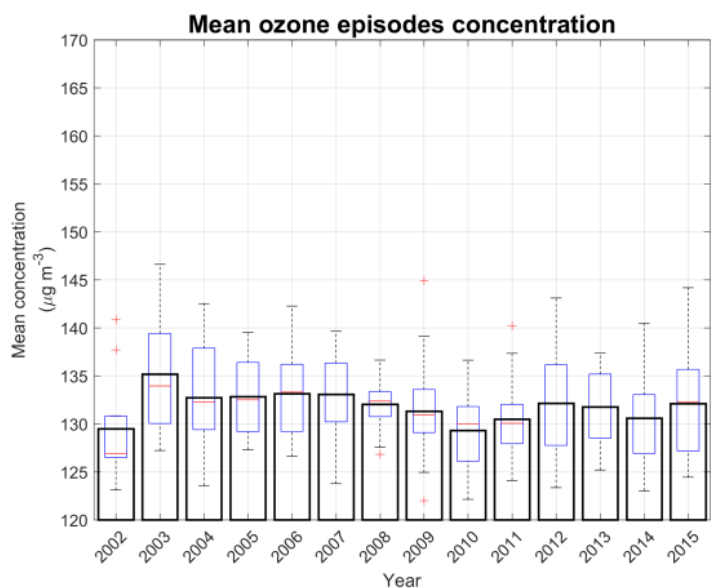

(d)

Figure 6. Cluster analysis of the maximum 8-hour-average ozone. A cluster is defined as a subset of consecutive days exceeding the LTO threshold. (a) Number of clusters; (b) Cluster duration (days); (c) Maximum cluster concentration; (d) Mean cluster concentration. Solid bars denote average over stations, boxplots display the distribution of data from each station. 
The 1st International Electronic Conference on Atmospheric Sciences (ECAS 2016), 16-31 July 2016; Sciforum Electronic Conference Series, Vol. 1, 2016

Figure 7 reports for each year, details on temperature clusters. The number of temperature events for the period 2002-2015 has an irregular temporal trend with the maximum value in the year 2014. However, similarly to ozone clusters, the well-known heat wave of 2003 emerges for the mean duration of temperature events (about 12 days) (Figure $7 \mathrm{~b}$ ); the year 2008 is the second with almost 10 days, while 2006, 2012, 2013 and 2015 had temperature events of about 7-8 days. The year 2015 had the second hottest ozone season after 2003, with an average maximum and mean temperature of episodes of about $32{ }^{\circ} \mathrm{C}$ and $30{ }^{\circ} \mathrm{C}$, respectively (Figure 7c,d). 2008 had also high maximum and mean temperatures of $31.5^{\circ} \mathrm{C}$ and $30^{\circ} \mathrm{C}$, respectively. Apart from the outstanding case of 2003 , also the temperature cluster analysis confirms that the high ozone episodes are not straightforwardly linked to high temperature episodes only, and it suggests that the two types of episodes (high ozone and high temperature) may not be perfectly in phase.

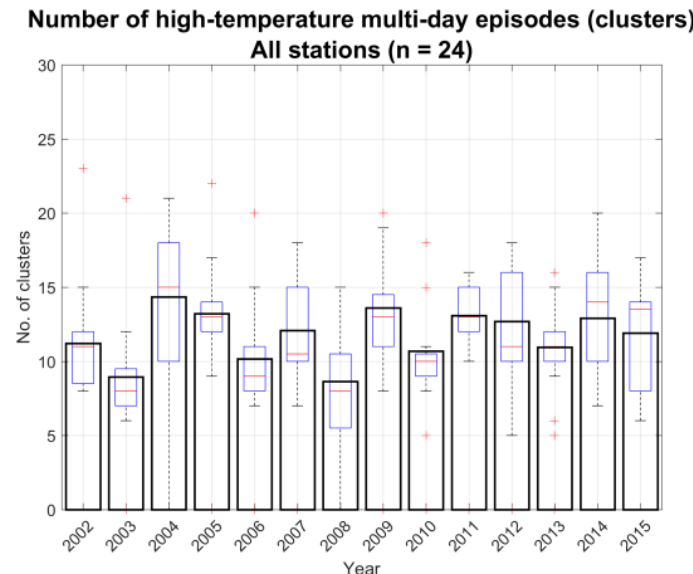

(a)

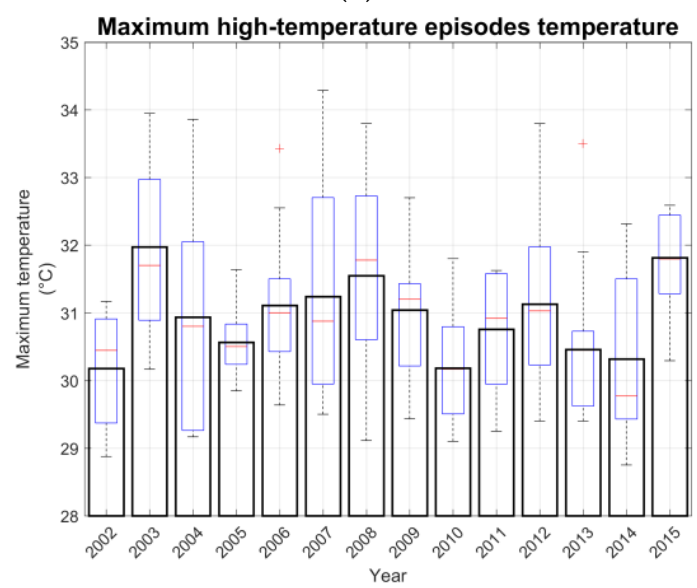

(c)

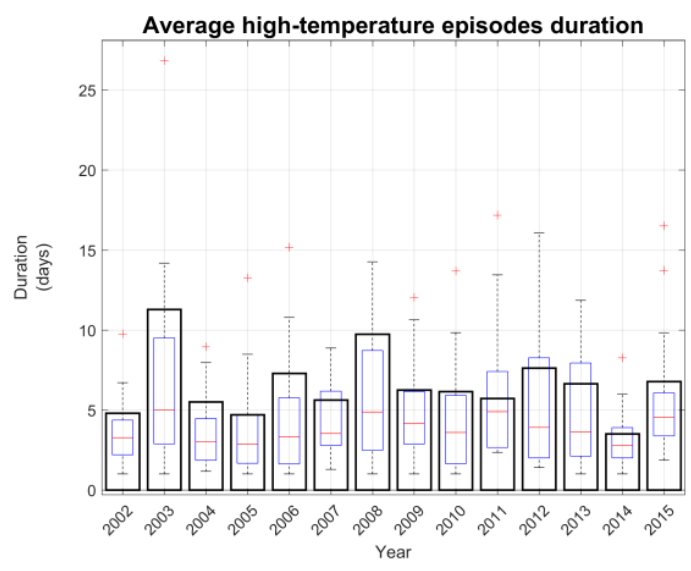

(b)

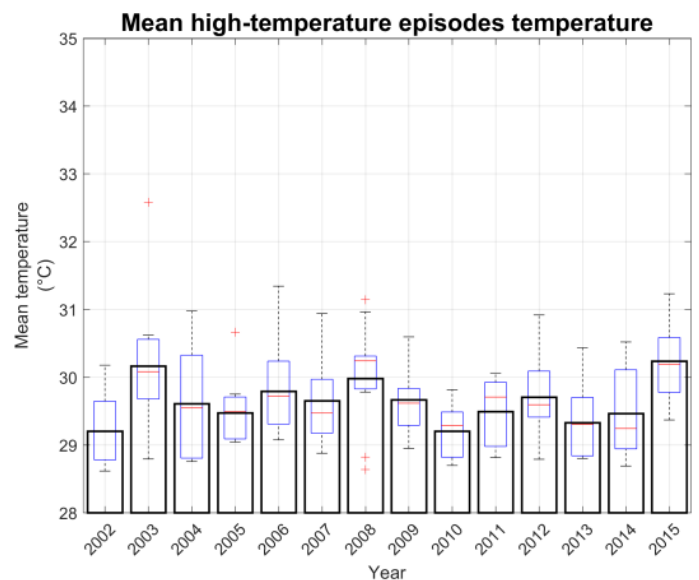

(d)

Figure 7. Same of Figure 6 but for daily maximum temperature. The threshold used to define a member of a cluster is $28^{\circ} \mathrm{C}$.

In Figure 8 the ozone cluster mean concentration is binned as a function of duration of the high ozone event (Figure 8a), of the high temperature event (Figure 8b), and of the intensity of the high temperature event (Figure 8c). The cluster ozone mean concentration grows monotonically with the increasing duration of the ozone episode (by roughly $2.5 \mu \mathrm{g} \cdot \mathrm{m}^{-3}$ per day), while it displays a maximum when grouped according to the duration of high temperature episodes. In particular, the maximum mean concentration is reached when the duration of temperature cluster is of 5-6 days, and it decreases for longer heat waves. This result is in qualitative agreement with the results of [15], who also reported a peak of the ozone concentration around the length of 6 days of heat waves over 
The 1st International Electronic Conference on Atmospheric Sciences (ECAS 2016), 16-31 July 2016;

Sciforum Electronic Conference Series, Vol. 1, 2016

Greece. The same result also confirms that ozone events and heat waves do not occur at the same time and that their durations are not linearly dependent.

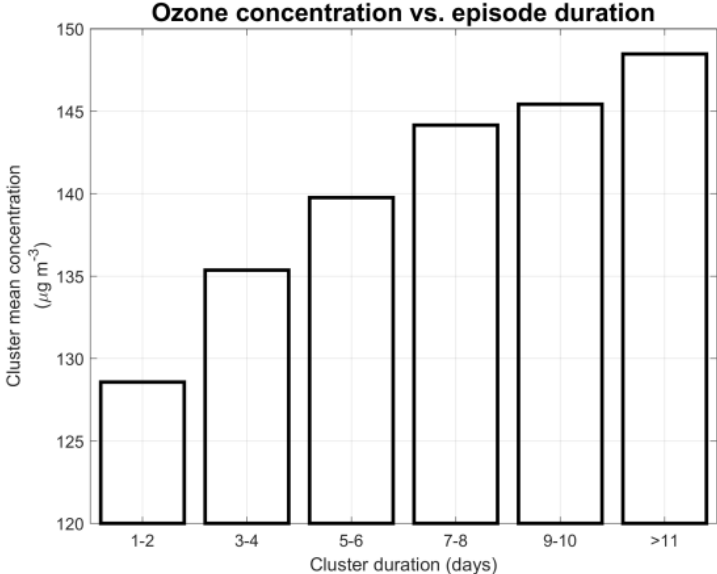

(a)

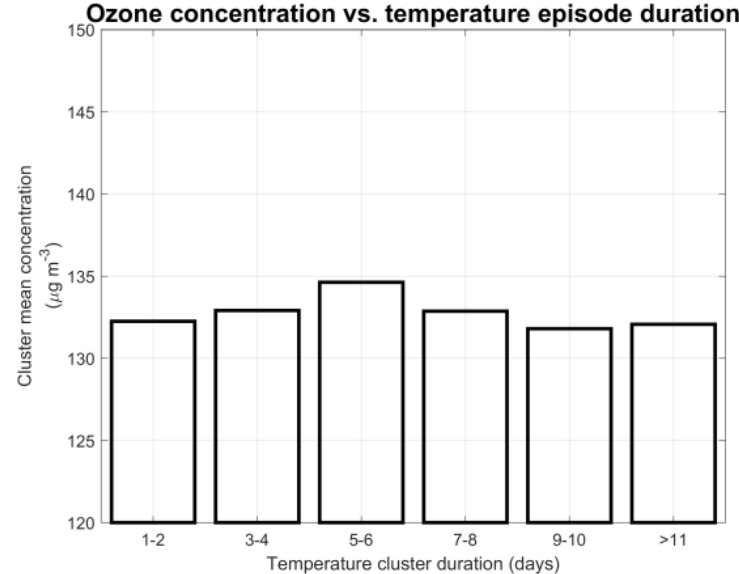

(b)

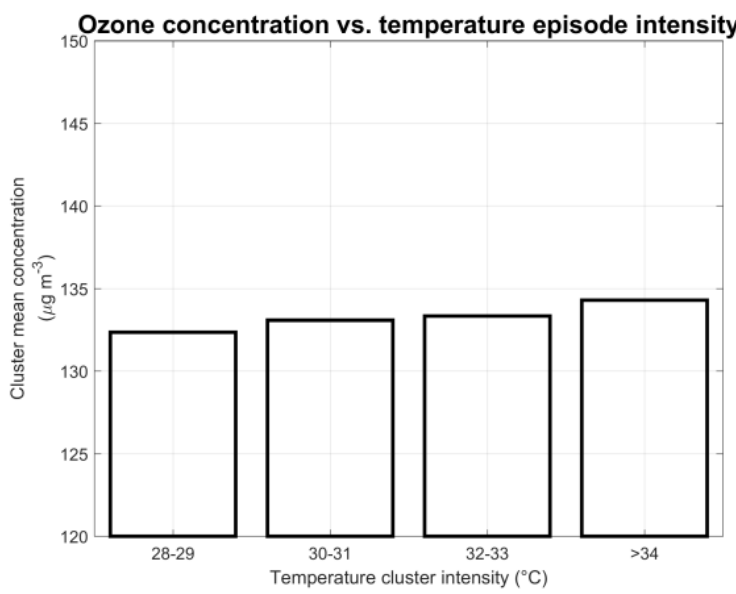

(c)

Figure 8. Histograms of the cluster mean concentration binned according to: (a) duration of the ozone clusters; (b) duration of the temperature clusters; (c) mean temperature of temperature clusters.

The mean concentration of shortest ozone events (1-2 days) is less than $130 \mu \mathrm{g}^{-3} \mathrm{~m}^{-3}$, while it is almost $150 \mu \mathrm{g} \cdot \mathrm{m}^{-3}$ for the longest events (>11 days). On the other hand, the ozone mean concentrations averaged during high temperature episodes ranges only from $132 \mu \mathrm{g} \cdot \mathrm{m}^{-3}$ to $135 \mu \mathrm{g} \cdot \mathrm{m}^{-3}$, confirming a radically different arrangement of ozone values when relating it to the duration of high ozone or high temperature events. Furthermore, Figure $8 \mathrm{c}$ shows that the mean concentration of ozone events grows from $133 \mu \mathrm{g} \cdot \mathrm{m}^{-3}$ to $135 \mu \mathrm{g} \cdot \mathrm{m}^{-3}$ with increasing mean value of temperature events from $28{ }^{\circ} \mathrm{C}$ to more than $34{ }^{\circ} \mathrm{C}$. Therefore, our analyses do not observe the phenomenon of ozone suppression at high temperatures recognized in the US by $[8,9]$.

\section{Conclusions}

Surface ozone data was analysed from 24 air quality monitoring stations over Italy for the ozone seasons (May-September) in the period 2002-2015, in order to study how the heat wave of 2015 affected the related ozone season. Stations have been sorted into six groups according to the zone (rural, suburban and urban) and to the geographical location inside or outside the Po Valley (one of the most polluted areas in Europe, covering Northern Italy). 
The 1st International Electronic Conference on Atmospheric Sciences (ECAS 2016), 16-31 July 2016;

Sciforum Electronic Conference Series, Vol. 1, 2016

First, we focused on the number of exceedences of limit values for each year, as set by the European directive. Afterwards, we arranged the data in subsets of multi-day high ozone episodes and analyzed the properties of these clusters (number, duration, maximum and mean value). We also explored the relationship of high ozone episodes with temperature.

We found that the highest number of exceedences of the daily maximum 8-hour average ozone was reached during the notable hot year 2003 (65 per station). 2015 was one of the hottest years after 2003 (average maximum temperature of almost $28^{\circ} \mathrm{C}$ and $29^{\circ} \mathrm{C}$, respectively), and the related ozone season was one of the most severe in recent years (38 exceedences per station), especially at rural sites (70 per station). We noted that, during the period 2002-2015, the average number of exceedences per station is often higher than 25 per year, which is the limit allowed by the European directive.

We confirm that ozone levels exceed limits more ofter in Po Valley with respect to the rest of the country, although average temperatures are generally lower by $2-3^{\circ} \mathrm{C}$. Indeed, we found that ozone is more sensitive to temperature inside the Po Valley, especially at urban stations. Outside Po Valley, ozone sensitivity to temperature is generally higher at rural stations and lower at urban stations. We noted a decreasing tendency of the sensitivity from 2003 to 2011, afterwards there is an inversion of tendency. The trend may be, at least in part, related to the programmed reduction of $\mathrm{NO}_{\mathrm{x}}$ emissions.

Cluster analysis shows that the 2015 ozone season was peculiar in terms of the duration of the events: on average, the high ozone episodes lasted almost 4 days, compared to less than 3 days for recent years. This is not perfectly consistent with the duration of high temperature events, which in 2015 had similar or shorter duration with respect to other recent years. This suggests that temperature is not the only indicator of high ozone pollution events, and that high temperature and high ozone episodes may not be in phase.

The latter observation is confirmed when arranging the intensity of the ozone events (measured here by the mean 8-hour ozone concentration) as a function of high ozone episode duration vs. high temperature episode duration. We found that ozone mean concentration grows monotonically with the increasing duration of the ozone episode (by roughly $2.5 \mu \mathrm{g} \cdot \mathrm{m}^{-3}$ per day), while it displays a maximum when grouped according to the duration of high temperature episodes. In particular, the maximum mean concentration is reached when the duration of temperature cluster is of 5-6 days, and it decreases for longer heat waves. Furthermore, we found a modest linear growth of the mean concentration of ozone events of about $0.3 \mu \mathrm{g} \cdot \mathrm{m}^{-3}$ per ${ }^{\circ} \mathrm{C}$; therefore, we do not observe the phenomenon of ozone suppression at high temperatures previously reported for the US.

The work presented here set a first overview of the ozone problem over Italy in recent years. More investigation is needed to interpret the features reported here, in particular it would be desirable to relate their interpretation to the changing ozone precursor emissions (in particular $\mathrm{NO}_{x}$ and VOCs) and to meteorological variables other than temperature. On the latter point, past work carried out on other areas of the world or on single localtions (e.g., [6,11]) highlighted the importance of including information also on the atmospheric stability and humidity, when interpreting ozone concentrations trends. A quantile regression could be, moreover, useful for the characterization of the meteorological influence on ozone at high concentrations [6]. The determination of a robust relationship between meteorological factors and high ozone levels might be then used to extrapolate expectations on the future ozone seasons under climate change projections.

Acknowledgments: The authors acknowledge the Regional Environmental Protection Agencies (ARPAs) for providing the ozone concentration data for years 2013-2015. The Italian Ministry for Economic Development (MISE) and Istituto Zooprfilattico dell' Abruzzo e del Molise "G. Caporale" are acknowledged for funding S.F.

Author Contributions: G.C. conceived the study; S.F. collected the data and performed the analysis; S.F., A.C., C.I., and G.C. discussed the analysis; S.F. and G.C. wrote the paper.

Conflicts of Interest: The authors declare no conflict of interest. 
The 1st International Electronic Conference on Atmospheric Sciences (ECAS 2016), 16-31 July 2016;

Sciforum Electronic Conference Series, Vol. 1, 2016

\section{Abbreviations}

The following abbreviations are used in this manuscript:

LTO long-term objective (EU directive), i.e., the limit value of $120 \mu \mathrm{g} \cdot \mathrm{m}^{-3}$ for the daily maximum 8-hour average ozone concentation

IT information threshold (EU directive), i.e., the limit value of $180 \mu \mathrm{g} \cdot \mathrm{m}^{-3}$ for the 1-hour average ozone concentration alarm threshold (EU directive), i.e., the limit value of $240 \mu \mathrm{g} \cdot \mathrm{m}^{-3}$ for the 1-hour average ozone concentration

\section{References}

1. World Health Organization; Scovronick, N. Reducing Global Health Risks Through Mitigation of Short-Lived Climate Pollutants. Scoping report for policy-makers. ISBN: 978924156508 0, 2015.

2. Jenkin, M.E.; Clemitshaw, K.C. Ozone and other secondary photochemical pollutants: Chemical processes governing their formation in the planetary boundary layer. Atmos. Environ. 2000, 34, 2499-2527.

3. Jacob, J.J.; Winner, D.A. Effect of climate change on air quality. Atmos. Environ. 2009, 43, 51-63.

4. Demuzere, M.; Trigo, R.M.; Vila-Guerau de Arellano, J.; van Lipzig, N.P.M. The impact of weather and atmospheric circulation on $\mathrm{O}_{3}$ and $\mathrm{PM}_{10}$ levels at a rural mid-latitude side. Atmos. Chem. Phys. 2009, 9, 2695-2714.

5. Demuzere, M.; van Lipzig, N.P.M. A new method to estimate air-quality levels using a synoptic-regression approach. Part I: Present-day $\mathrm{O}_{3}$ and PM10 analysis. Atmos. Environ. 2010, 44, 1341-1355.

6. Porter, W.C.; Heald, C.L.; Cooley, D.; Russel, B. Investigating the observed sensitivities of air-quality extremes to meteorological drivers via quantile regression. Atmos. Chem. Phys. 2015, 15, 10349-10366.

7. Bloomer, B.J.; Stehr, J.W.; Piety, C.A.; Salawitch, R.J; Dickerson, R.R. Observed relationships of ozone air pollution with temperature and emissions. Geophys. Res. Lett. 2009, 36, L09803, doi:10.1029/2009GL037308.

8. Steiner, A.L.; Davis, A.J.; Sillman, S.; Owen, R.C.; Michalak A.M.; Fiore A.M. Observed suppression of ozone formation at extremely high temperatures due to chemical and biophysical feedbacks. In Proceedings of the National Academy of Sciences, 2010, doi:10.1073/pnas.1008336107.

9. Shen, L.; Mickley, L.J.; Gilleland, E. Impact of increasing heat waves on U.S. ozone episodes in the 2050s: Results from a multimodel analysis using extreme value theory. Geophys. Res. Lett. 2016, 43, 4017-4025.

10. Sillman, S.; Samson, P.J. Impact of temperature on oxidant photochemistry in urban, polluted rural and remote environments. Geophys. Res. Lett. 1995, 100, 497-508.

11. Di Carlo, P.; Pitari, G.; Mancini, E.; Gentile, S.; Pichelli, E.; Visconti, G. Evolution of surface ozone in central Italy based on observations and statistical model. J. Geophys. Res.: Atmos. 2007, 112, D10316, doi:10.1029/2006JD007900.

12. Curci, G.; Beekmann, M.; Vautard, R.; Smiatek, G.; Steinbrecher, R.; Theloke, J.; Friedrich, R. Modelling study of the impact of isoprene and terpene biogenic emissions on European ozone levels. Atmos. Environ. 2009, 43, 1444-1455.

13. Bigi, A; Ghermandi, G. Long-term trend and variability of atmospheric PM10 concentration in the Po Valley. Atmos. Chem. Phys. 2014, 14, 4895-4907.

14. Directive 2008/50/EC of the European Parliament and of the Council of 21 May 2008 on ambient air quality and cleaner air for Europe.

15. Papanastasiou, D.K.; Melas, D.; Kambezidis H.D. Heat waves characteristics and their relation to air quality in Athens. Glob. NEST J. 2014, 16, 919-928.

(C) 2016 by the authors; licensee MDPI, Basel, Switzerland. This article is an open access article distributed under the terms and conditions of the Creative Commons by Attribution (CC-BY) license (http://creativecommons.org/licenses/by/4.0/). 